\title{
A Viable Rehabilitation Approach with Maxillary Cast Partial Denture and Mandibular Over Denture - A Case Report
}

\author{
Pradhan $\mathrm{B}^{1}$, Joshi S P $\mathrm{P}^{2}$, Verma $\mathrm{A}^{3}$ \\ ${ }^{1}$ PG Resident, Department of Prosthodontics, National Academy of Medical Sciences, Bir Hospital, Kathmandu \\ ${ }^{2}$ Professor, Department of Prosthodontics, National Academy of Medical Sciences, Bir Hospital, Kathmandu \\ ${ }^{3}$ Assistant Professor, Department of Prosthodontics, National Academy of Medical Sciences, Bir Hospital, Kathmandu
}

\begin{abstract}
Prosthodontic rehabilitation is indicated to restore function, esthetics and phonetics. The prosthetic options for rehabilitation of partial edentulism include removable partial dentures (RPD), overdentures, and implant supported prosthesis. Any tooth replacement should be performed by a detailed evaluation of the existing dental situation and functional condition of the patient. Besides, the risks, benefits and costs of the selected treatment modality should be discussed with the patient. Choice of prosthetic treatment modality is mainly determined by the patient's needs and expectations, social and economic aspects, educational level, as well as the general health status, oral functional benefits, esthetics, prognosis of the remaining teeth and patient motivation to maintain oral hygiene.

This clinical report describes rehabilitation of a partially edentulous patient with maxillary cast partial denture (CPD) and mandibular tooth supported overdenture.
\end{abstract}

Key words: Cast Partial Dentures, Partial edentulism, removable partial dentures (RPD), over dentures

\section{Introduction}

$\mathrm{E}$ dentulism is a debilitating and irreversible condition and is described as the "final marker of disease burden for oral health." It remains a major disease worldwide, especially among older adults. ${ }^{2}$ Partial edentulism is defined as the absence of some but not all of the natural teeth in a dental arch. In a partially edentulous patient, the loss and continuing degradation of the alveolar bone, adjacent teeth, and supporting structures influence the level of difficulty in achieving adequate prosthetic restoration. ${ }^{3-5}$

Treatment options for partially edentulous patients with missing single or multiple teeth

*Corresponding Author
Dr. Bismita Pradhan
PG Resident
Department of Prosthodontics
National Academy of Medical Sciences, Bir Hospital,
Kathmandu
E-mail: vbismita@gmail.com

range from a provisional removable partial denture, a definitive cast partial denture, fixed partial denture and Implant supported prosthesis.

This article describes rehabilitation of partially edentulous patient with removable cast partial denture in the maxillary arch and tooth supported overdenture in the mandibular arch to enhance esthetics and restore function.

\section{Case report}

A 72-year-old male patient reported to Dental Department, Prosthodontic Unit of Bir Hospital with a chief complaint of difficulty in chewing due to missing teeth in upper and lower jaws and wanted replacement for the missing teeth. There was no relevant medical history affecting prosthodontic treatment. On extraoral examination, patient had decreased facial height. Intra oral examination revealed Kennedy's Class I partially edentulous maxillary arch (Fig 1). Dental caries were detected in 14, 24 and cervical abrasion with respect to $11,13,21,22,23$ respectively. The only 
teeth present in mandibular arch were 33 and 43 (fig 2). Radiographic examination revealed good bone support and long roots with respect to 33,43 which was ideal for tooth supported overdenture.

Treatment options were explained to the patient along with the advantages and disadvantages of each treatment option. The patient decided to go for the CPD in maxillary arch and tooth supported overdenture in the mandibular arch. Implant retained prosthesis was refused by the patient because of needed additional surgery, the longer duration of treatment phase and related expenditure. Treatment plan included oral prophylaxis, restoration of cervical abrasions in respect to $11,13,21,22,23$, root canal treatment in respect to 14,24 and 33,43 which were chosen as over denture abutments.

Oral Prophylaxis was carried out and primary impressions were made with irreversible hydrocolloid impression material (Zelgan; Dentsply Ltd). Diagnostic casts were fabricated with Type III Dental Stone and maxillary cast obtained was surveyed. Design of the CPD included antero-posterior palatal strap as major connector, occlusal rest in respect to 13,14 and 23,24 . Due to attrition in maxillary canines (13, 23 ) instead of the cingulum rests, occlusal rests were planned. RPI system was used as clasp assembly in respect to 14 and 24.

Tooth preparation was done in respect to 14,24 for the metal ceramic crown with mesio occlusal rest seats. Final impression was made using light body and putty consistency addition silicone. Wax patterns for the metal ceramic crowns were surveyed to obtain the favorable parallelism. Casting of the wax pattern was done and after verifying the fit of the metal ceramic crown in bisque stage, a pick up impression was made. The impression was poured with type IV dental stone. The master cast along with bisque stage metal ceramic crown was surveyed for clasp positioning (fig 3).

The final glazed crowns were cemented irt 14 and 24 using luting cement (GC gold label luting and lining cement, Japan) (Fig 4). Final impression was made in the next appointment with light body and medium body addition silicone impression material using a custom tray. Cast was poured with type IV dental stone (Fig 5).

The cast was surveyed and after block out, it was duplicated to obtain a refractory cast. Wax pattern was made according to the proposed design and casting was done (fig 6). Try in of the metal framework was carried out to verify the fit.

In the mandibular arch, overdentures abutments were prepared into dome shaped contour, 3-4 $\mathrm{mm}$ height, projecting just above the gingiva with 2-3 mm post space. Impression was made using the putty wash technique. Fabricated metal copings for overdenture were cemented. (fig 7)

Primary impression of the lower arch was made with alginate and a special tray was fabricated on the cast after block out. Using conventional techniques, border molding was done and secondary impression was made with light body addition silicone (Fig 8). Impression was poured with type III dental stone (Fig 9).

Wax occlusal rims were fabricated in both the maxillary (Fig 10) and mandibular arches and occlusal vertical dimension was recorded. Facebow transfer (Fig. 11) and registration of the centric relation were carried out (Fig. 11) and the casts were articulated in Hanau Wide Vue semi-adjustable articulator (Fig 12). Teeth arrangement and try in was done (Fig 13). Then it was processed in heat cure acrylic resin, adjusted, finished, polished and delivered to the patient. Post insertion instructions were given. (Fig 14-17)

Follow up visits - The patient was recalled after $24 \mathrm{hrs}$ and minor adjustments were made. Then subsequent recalls were made for adjustments and evaluation. 


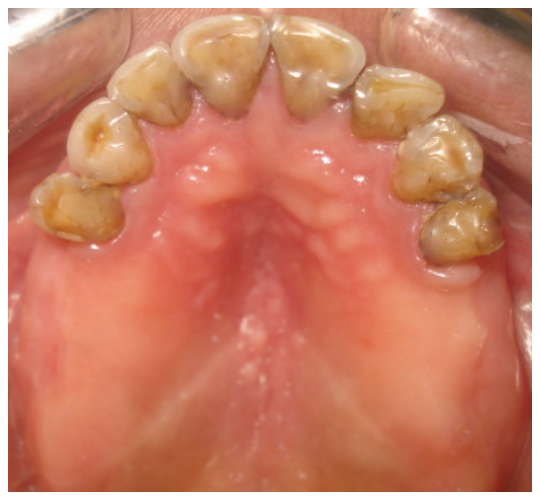

Figure 1: Maxillary arch

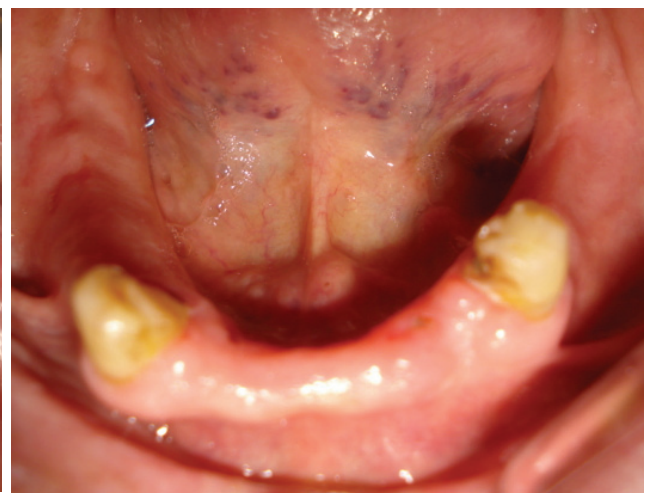

Figure 2: Mandibular arch

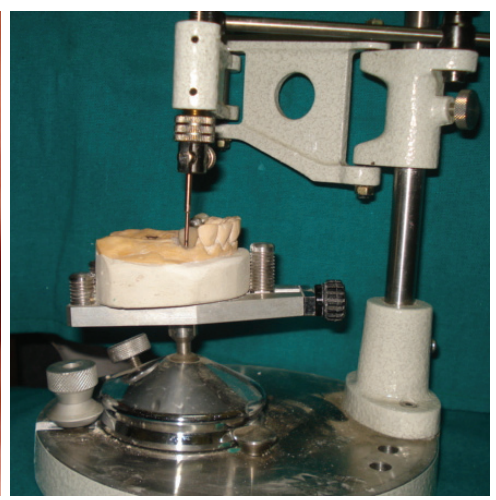

Figure 3: Surveying of metal ceramic crown in bisque stage
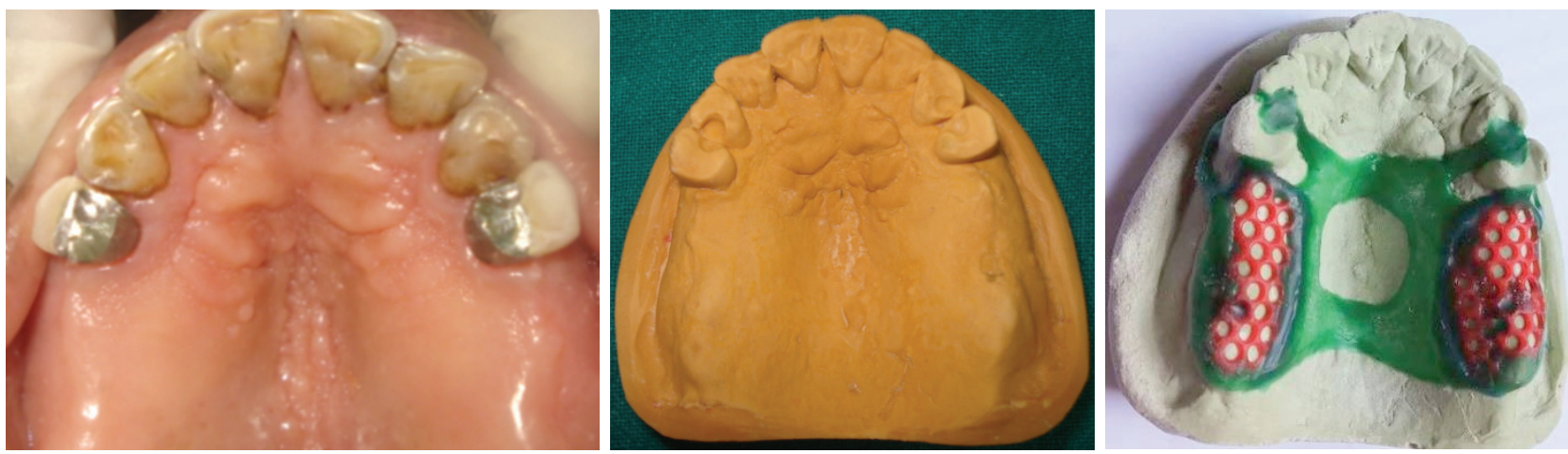

Figure 4: Luted Ceramic facing crown Figure 5: Master cast with occlusal rest seat irt 14 and $24 . \quad$ (maxillary arch) with prepared rest seat)

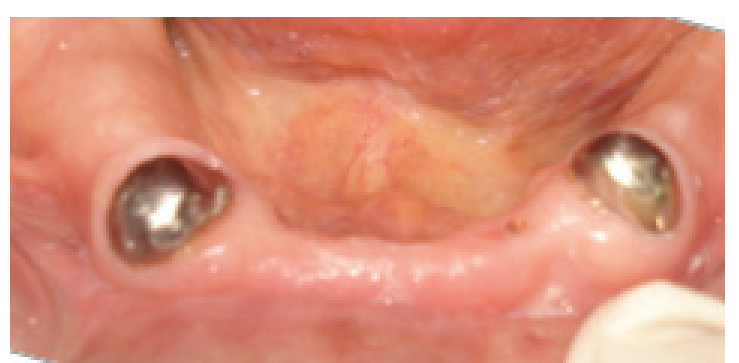

Figure 7: Metal coping after cementation

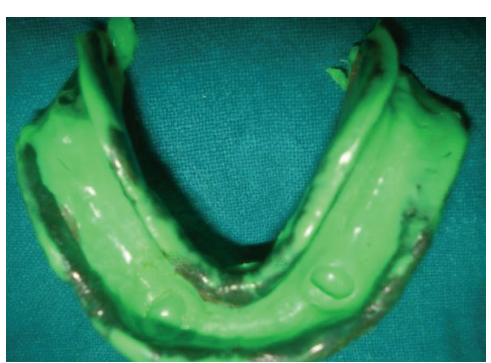

Figure 8: Border molding and Figure 9: Master cast final impression of mandibular (Mandibular arch) arch by medium body elastomer using custom tray.

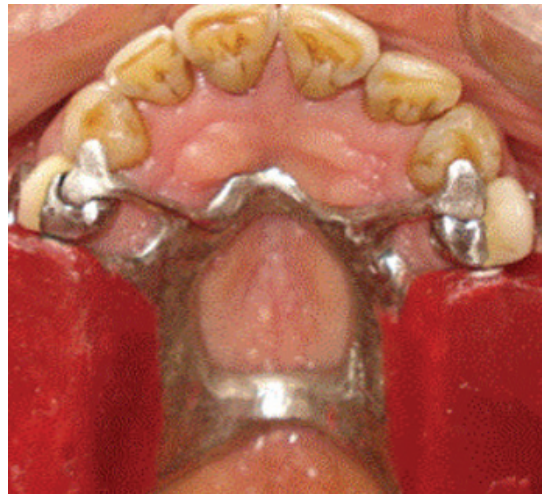

Figure 10: Maxillary occlusal rim Figure 11: Facebow transfer with metal framework

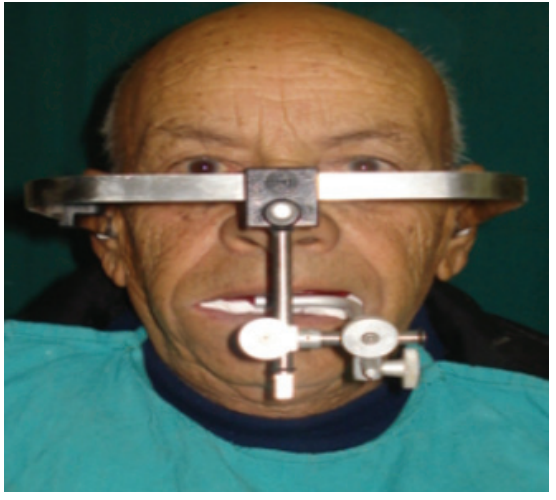

Figure 12: Mounting of cast in semi adjustable articulator 


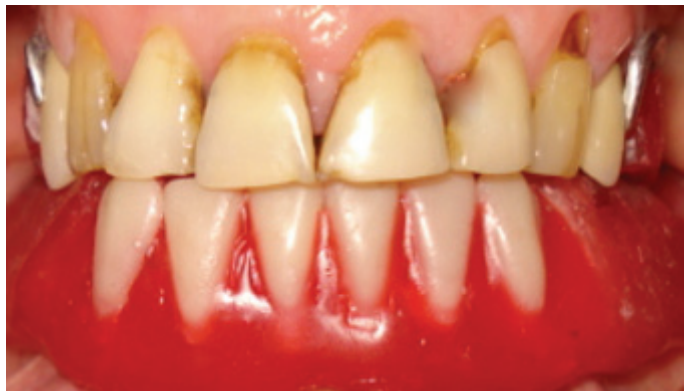

Figure 13: Anterior try- in

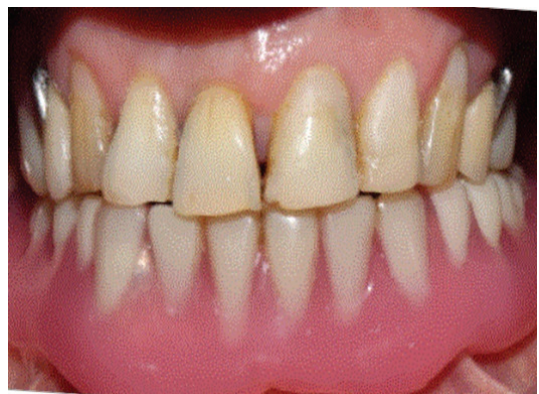

Figure 14: Insertion of Maxillary CPD and Mandibular overdenture

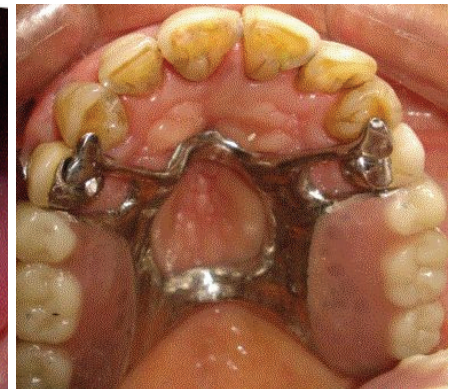

Fig 15: Maxillary CPD

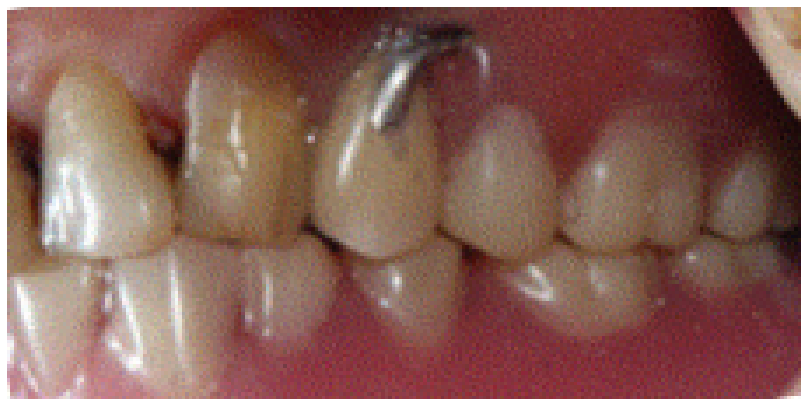

Figure 16: Left lateral view

\section{Discussion}

There are several treatment options for rehabilitation of the partially edentulous patients. Newer technologies like CAD CAM, precision milled attachments, implant supported prosthesis and impression materials have been improving the quality of RPD. ${ }^{4}$

The choice of treatment is also critically dependent on the status of the abutment teeth, which are often periodontally involved. ${ }^{5}$ The stress on the abutment due to the difference in nature and behavior of the tissues supporting RPD is critical for long term success of prosthesis. In this case, the stress control on abutment is achieved through dual impression technique, broad coverage and stable denture base, rigid design, and clasp design. ${ }^{6} \mathrm{CPD}$ was given in maxillary arch without precision attachment due to poor economic condition of patient and time limitation. Full coverage crown was given irt 14 and 24 to protect the abutments and provide best possible support for occlusal rest. In RPI clasp assembly design,

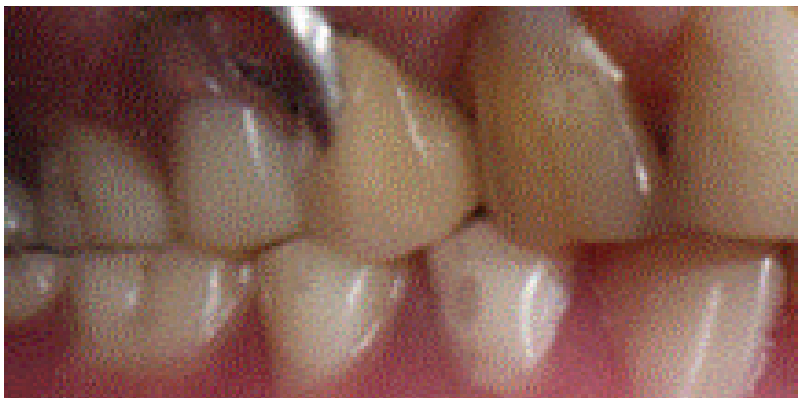

Figure 17: Right lateral view

the primary aim of a mesial rest is to alter the fulcrum position and resultant clasp movement, Preventing harmful engagement of abutment tooth due to Class I lever action. ${ }^{7}$ Considering this advantage, RPI class assembly was used irt 14 and 24.

A number of literatures have highlighted the importance of overdentures. In 1967 and 1969 Tallgren ${ }^{8}$ showed $7 \mathrm{yr}$ reduction of anterior ridge height of mandible 4 times greater than maxillary edentulous ridge. Atwood and Coy (1972) supported Tallgren's finding of 4:1 bone loss between mandibular and maxillary edentulous ridge. The results of a 5-year clinical study by Crum RJ Rooney ${ }^{9}$ has shown that patients treated with the complete maxillary dentures and the mandibular overdentures demonstrate less vertical alveolar bone reduction than patients with the complete maxillary and mandibular dentures. Retained root abutments can give better retention, support, and stability to an overdenture and also provide proprioception that would otherwise be lost with conventional 
denture treatment. ${ }^{10}$ Extracoronal restorations (copings) over relatively porous dentinal surfaces protect overdenture abutments from penetration by microorganisms and prevent caries. ${ }^{11}$ Tooth supported mandibular over denture with metal copings were given on abutment tooth to protect the abutment tooth from dental caries.

\section{Conclusion}

Among various options to rehabilitate partially edentulous patients, cast partial dentures are viable options where other treatment alternatives like implants and fixed partial dentures are not possible. They provide good functional ability and satisfactory esthetics.

Tooth supported overdentures are a simple and cost-effective alternative treatment for enhancing the retention and prevention of ridge resorption. It is a favored treatment modality for elderly patients with few remaining teeth. Proper diagnosis, systematic treatment planning and periodic recall preventive therapy is however a key to successful treatment and patient satisfaction.

\section{References}

1. Emami E, de Souza RF, Kabawat M, Feine JS. The impact of edentulism on oral and general health. Int J Dent. 2013;2013:498305.

2. Douglass CW, Shih A, Ostry L. Will there be a need for complete dentures in the United States in 2020?. The Journal of prosthetic dentistry. 2002, 1;87(1):5-8.
3. Shrestha P, Bhagat T. Partial Edentulism in Patients Visiting the Dental Out-Patient Department at the Tertiary Care Centre in the Eastern Part of Nepal. J Nep Prosthdont Soc. 2018,30;1(1):33-7.

4. Eggbeer D, Bibb R, Williams R. The computer-aided design and rapid prototyping fabrication of removable partial denture frameworks. Proceedings of the Institution of Mechanical Engineers, Part H: J Eng in Med. 2005,1;219(3):195-202.

5. D'Souza DS, Dua P. Rehabilitation strategies for partially edentulous-prosthodontic principles and current trends. Med J Armed Forces Ind. 2011,1;67(3):296-8.

6. Kukunoor S, Savadi RC, Raju KV, Kumar S. A Viable Treatment Alternative in Distal Extension Cases: A Case Report. The Journal of Indian Prosthodontic Society. 2014 Dec 1;14(1):177-80.

7. Henderson D, McCracken WL, McGivney GP, Castleberry DJ. McCracken's removable partial prosthodontics. CV Mosby Company; 1985.

8. Tallgren A. Positional Changes of Complete Dentures a 7-Year Longitudinal Study. Acta odontologica scandinavica. 1969,1;27(5):53961.

9. Crum RJ, Rooney Jr GE. Alveolar bone loss in overdentures: a 5-year study. J Prosthet Dent. 1978,1;40(6):610-3.

10. Morrow RM, FeldmannEE, Rudd KD, Trovillion HM. Tooth-supported complete dentures: an approach to preventive prosthodontics. J Prosthet Dent. 1969,1;21(5):513-22.

11. Fosse G, Saele PK, Eide R. Numerical density and distributional pattern of dentin tubules. Acta Odontologica Scandinavica. 1992,1;50(4):20110. 